\title{
MEMBANGUN VISUALISASI 3D GEDUNG STMIK WIDYA CIPTA DHARMA BERBASIS AUGMENTED REALITY PADA BROSUR PENERIMAAN MAHASISWA BARU
}

\author{
Siti Lailiyah ${ }^{1)}$, Reza Andrea ${ }^{2)}$, Mira Dewi Yustina ${ }^{3)}$ \\ ${ }^{1}$ Manajemen Informatika, STMIK Widya Cipta Dharma \\ ${ }^{2,3}$ Teknik Informatika, STMIK Widya Cipta Dharma \\ $1,2,3 \mathrm{Jl}$. M. Yamin No.25, Samarinda, 75123 \\ e-mail : lail.59a@gmail.com ${ }^{1)}$,reza@bibirdesign.com ${ }^{2}$, miirady@gmail.com ${ }^{3)}$
}

\begin{abstract}
ABSTRAK
Penyajian informasi dalam media promosi masih banyak menggunakan cara konvensional dan belum memadukan unsurunsur teknologi modern. Augmented Reality (AR) adalah bidang penelitian komputer yang menggabungkan data grafis 3 dimensi dengan dunia nyata atau dengan kata lain realita yang ditambahkan ke suatu media. Kegiatan pengenalan kampus STMIK Widya Cipta Dharma saat ini menggunakan media brosur yang berisi gambar 2 dimensi dan informasi mengenai kampus sehingga banyak calon mahasiswa baru yang kurang tertarik karena kurangya informasi mengenai fasilitas gedung yang dimiliki, namun akan sangat menarik jika gambar pada brosur disajikan dengan berbentuk 3 dimensi.

Visualisasi 3D gedung STMIK Widya Cipta Dharma berbasis augmented reality pada brosur penerimaan mahasiswa baru diawali dengan penginstalan software pendukung augmented reality, ARToolKit, kemudian merancang desain 3D objek gedung STMIK Widya Cipta Dharma menggunakan Google SketchUp, selanjutnya merancang desain marker dan desain brosur penerimaan mahasiswa baru menggunakan Adobe Photoshop CS3.

Berdasarkan hasil pengujian beta, Visualisasi 3D Gedung STMIK Widya Cipta Dharma Berbasis Augmented Reality pada Brosur Penerimaan Mahasiswa Baru ini dapat menjadi salah satu media alternatif untuk promosi pada calon mahasiswa baru dan menarik sebagai media promosi yang memperkenalkan bangunan STMIK Widya Cipta Dharma dengan cara yang lebih interaktif.
\end{abstract}

Kata Kunci: Visualisasi 3D, STMIK Widya Cipta Dharma, Brosur, Gedung 3D, Augmented Reality

\section{PENDAhULUAN}

Kebutuhan teknologi berkembang seiring dengan perkembangan zaman. Bermacam-macam teknologi telah diciptakan untuk berbagai keperluan dan pada berbagai bidang ilmu. Terutama di dalam bidang informasi, edukasi dan komunikasi. Adapun perkembangan ini menimbulkan dampak positif bagi para pemakai atau user.

Kebutuhan informasi dalam media promosi masih banyak menggunakan cara konvensional dan belum memadukan unsur-unsur teknologi modern. Salah satu bentuk teknologi yang berkembang sekarang yang dapat digunakan adalah augmented reality (AR).

Augmented Reality (AR) adalah bidang penelitian komputer yang menggabungkan data grafis 3 dimensi dengan dunia nyata atau dengan kata lain realita yang ditambahkan ke suatu media. Media ini dapat berupa kertas, sebuah marker atau penanda melalui perangkatperangkat input tertentu.

Teknologi ini tidak sepenuhnya menggantikan sebuah realitas, tapi menambahkan (augment) sebuah atau beberapa benda-benda maya dalam bentuk 2 atau 3 dimensi ke dalam lingkungan nyata 3 dimensi dan ditampilkan secara realtime atau waktu yang sebenarnya.
Dari segi kegiatan pengenalan kampus STMIK Widya Cipta Dharma menggunakan media brosur yang berisi gambar dan informasi mengenai kampus. Tentunya dengan cara tersebut dirasa masih kurang kreatif dan inovatif yang bisa saja mengurangi minat ataupun kurangnya informasi dalam hal fasilitas untuk calon mahasiswa baru.

Dengan adanya perpaduan teknologi modern yaitu visualisasi 3D dalam hal ini menggunakan Augment Reality, maka fasilitas yang akan dilihat oleh calon mahasiswa baru akan terasa lebih menarik dan membuat calon mahasiswa semakin mengerti tentang fasilitas yang diperkenalkan.

\section{RUANG LINGKUP PENELITIAN}

Permasalahan difokuskan pada :

1. Visualisasi yang akan ditampilkan adalah tampak luar Gedung A, B, C, dan Rektorat STMIK Widya Cipta Dharma

2. Augmented Reality (AR) ini hanya dapat dijalankan dengan menggunakan personal computer dan notebook yang telah memiliki fasilitas kamera digital internal ataupun eksternal.

3. Metode yang digunakan adalah Marker Augmented reality 
4. Marker dicetak pada perancangan brosur penerimaan mahasiswa baru TA 2016/2017

\section{BAHAN DAN METODE}

Adapun bahan dan metode yang gunakan dalam membangun aplikasi ini yaitu:

\subsection{Augmented Reality}

Menurut Ronald T.Azuma (1997) mendefinisikan Augmented reality sebagai penggabungan benda benda nyata dan maya di lingkungan nyata, berjalan secara interaktif dalam waktu nyata dan terdapat integrasi dan maya dimungkinkan dengan teknologi tampilan yang sesuai, interaktivitas dimungkinkan melalui perangkatperangkat input tertentu, danintegrasi yang baik memerlukan penjelasan yang efektif.Sedangkanmenurut Stephen Coward dan Mark Faila dalam bukunya yang berjudul Augmented reality a partical guide, mendefinisikan bahwa Augmented reality merupakan cara alami untuk mengeksplorasi objek 3D dan data, AR merupakan suatu konsep perpaduan antara visual reality dengan world reality. Sehingga objek objek virtual 2 dimensi (2D) teknologi AR, pengguna dapat melihat dunia nyata yang ada di sekelilingnya dengan penambahan obyek virtual yang dihasilkan komputer. Dalam buku "Hand Bookof Augmented reality", Augmented reality bertujuan menyederhan akan hidup pengguna dengan membawa informasi maya yang tidak hanya untuk lingkungan sekitar, tetapi juga untuk setiap melihat langsung lingkungan dunia nyata, seperti livestreaming video. AR meningkatkan pengguna presepsi dan interaksi dengan dunia nyata.

Menurut penjelasan Haller, Billinghurst dan Thomas (2007), riset Augment Reality bertujuan untuk mengembangkan teknologi yang memperbolehkan penggabungan secara realtime terhadap digital content yang dibuat oleh komputer dengan dunia nyata. Augmented reality meemperbolehkan pengguna melihat objek maya dua dimensi atau tiga dimensi yang diproyeksi terhadap dunia nyata. (Emerging Technologies of Augmented reality).

\subsection{Marker}

Marker merupakan sebuah gambar berpola khusus yang sudah dikenali oleh Template MemoryARToolkit. Dimana marker tersebut berfungsi untuk dibaca dan dikenali oleh kamera lalu dicocokkan dengan templateARToolkit. Setelah itu, baru kamera akan melakukan render objek 3D diatas marker.

Pada umumnya Marker yang bisa dikenali ARToolkit hanya marker dengan pola berbentuk kotak dengan bingkai hitam didalamnya. Akan tetapi seiring berkembangnya zaman banyak pengembang Augmented reality yang dapat membuat marker tanpa bingkai hitam.

\subsection{Marker Augmented Reality}

Menurut Chari (2008) Marker Augmented reality merupakan tipe Augmented reality yang mengenali marker dan mengidentifikasi pola dari marker tersebut untuk menambahkan suatu objek virtual ke lingkungan nyata. Marker merupakan ilustrasi persegi hitam dan putih dengan sisi hitam tebal, pola hitam ditengah persegi dan latar belakang putih. Contoh marker dapat dilihat pada gambar 1 .

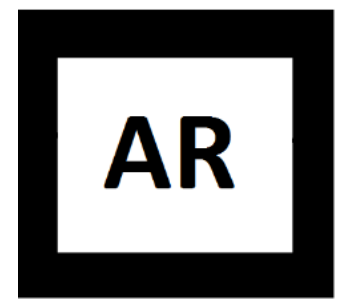

Gambar 1. Contoh Marker

Titik koordinat virtual pada marker berfungsi untuk menentukan posisi dari objek virtual yang akan ditambahkan pada lingkungan nyata. Posisi dari objek virtual akan terletak tegak lurus dengan marker. Objek virtual akan berdiri segaris dengan sumbu $\mathrm{Z}$ serta tegak lurus terhadap sumbu X (kanan atau kiri) dan sumbu Y (depan atau belakang) dari koordinat virtualmarker. Ilustrasi dari titik koordinat virtualmarker dapat dilihat pada gambar 2 .

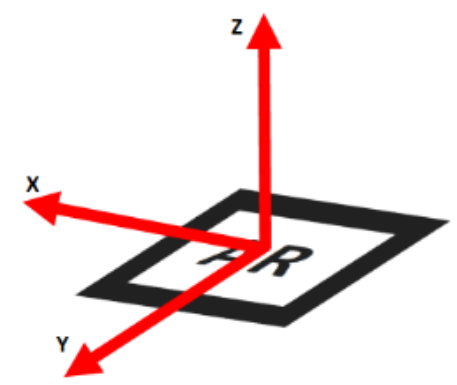

Gambar 2. Titik Koordinat Virtual pada Marker

\subsection{ArtoolKit}

Pengertian ARToolkit secara luas adalah software library untuk membangun Augmented reality dan aplikasi ini adalah aplikasi yang melibatkan overlay pencitraan virtual ke dunia nyata Untuk melakukan hal tersebut, ARToolkit menggunakan cara dengan pelacakan video, agar dapat menghitung posisi kamera yang nyata dengan mengorientasikan pola pada kertas marker secara realtime. Dari semua software library, ARToolkit adalah salah satu software library yang paling klasik dan yang pertama kali dibuat didunia oleh seorang ilmuan Jepang bernama Hirokazu Kato.

ARToolkit memberikan kemudahan dalam penggunaan bagi user yang sedang belajar Augmented reality jika dibandingkan dengan software library lainnya. Selain dari segi kemudahan dalam penggunaannya, ternyata software libraryARToolkit juga bersifat open source sehingga siapapun dapat memodifikasi ARToolkit tanpa harus membayar lisensi sepeserpun.

\subsection{Google SketchUp}

Menurut Manullang (2014), SketchUp merupakan sebuah program pemodelan tiga dimensi yang dirancang untuk insinyur arsitek, sipil, dan mekanik serta pembuatan film, game developer dan profesi terkait. Darmawan (2009), SketchUp merupakan sebuah program grafis yang diproduksi oleh Google. Program ini memberikan hasil utama yang berupa gambar sketsa grafik 3 dimensi. 
Hal lain yang terkait antara Google SketchUp dengan Augmented Reality adalah dalam hal pembuatan objek 3D, dengan cara lebih sederhana dan tidak menggunakan terlalu banyak tools. Sehingga pada saat pengerjaannya, proses pembuatan objek 3D akan lebih cepat dan mudah. Tidak hanya itu saja, dengan menggunakan Google SketchUp versi pro, penelitian dapat langsung mengekspor hasil gambar 3D ke format .wrl. Format inilah yang nantinya akan dibutuhkan ARToolkit untuk melakukan rendering objek ketika marker dihadapkan pada kamera.

\subsection{Tahapan Pengembangan Multimedia}

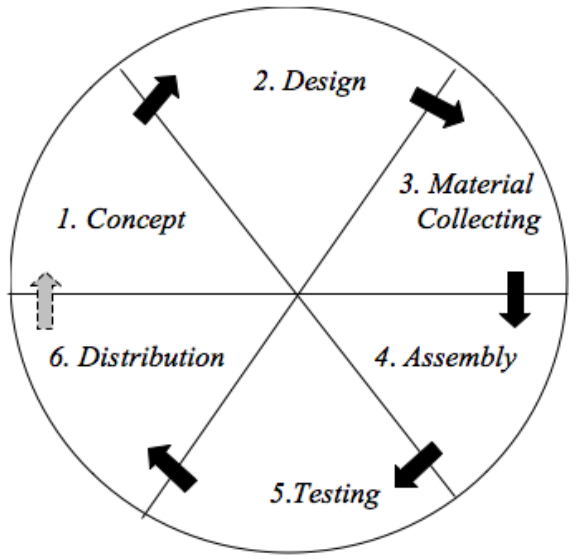

\section{Gambar 3. Tahapan Pengembangan Multimedia}

Dapat dilihat pada gambar 3 tahapan pengembangan multimedia meliputi (Binanto, 2010) :

\section{Concept}

Tahapan concept (pengonsepan) adalah tahap untuk menentukan tujuan dan siapa pengguna program (indentifikasi audiens). Tujuan dan penguna akhir program berpengaruh pada nuansa multimedia sebagai pencerminan dari indentitas organisasi yang menginginkan informasi sampai pada pengguna akhir. Karakteristik pengguna termasuk kemampuan pengguna juga perlu dipertimbangkan karena dapat memengaruhi pembuatan desain.

Selain itu, tahap ini juga akan menentukan jenis aplikasi (presentasi, interaktif, dan lain-lain) dan tujuan aplikasi (hiburan, pelatihan, pembelajarandan lain-lain). Dasar aturan untuk perancangan juga ditentukan pada tahap ini, misalnya ukuran aplikasi, target, dan lain-lain. Output dari tahap ini biasanya berupa dokumen yang bersifat naratif untuk mengungkapkan tujuan projek yang ingin dicapai.

Permasalahan difokuskan pada :

a. Fasilitas yang akan diperkenalkan pada brosur ini hanya fasilitas bangunan-bangunan utama tampak luar yang dimiliki oleh STMIK Widya Cipta Dharma

b. Augment Reality (AR) ini hanya dapat dijalankan dengan menggunakan personalcomputer dan notebook yang telah memiliki fasilitas kamera digital internal ataupun eksternal.

c. Metode yang digunakan adalah Marker Based Tracking d. Kemiripan objek 3D yang dibuat disesuaikan dengan PC/notebook yang digunakan.

2. Design

Design (perancangan) adalah tahap pembuatan spesifikasi mengenai arsitektur program, gaya, tampilan, dan kebutuhan material/bahan untuk program. Spesifikasi dibuat serinci mungkin sehingga pada tahap berikutnya, yaitu material collecting dan assembly, pengambil keputusan baru tidak diperlukan lagi, cukup menggunakan keputusan yang sudah ditentukan pada tahap ini. Meskipun demikian, pada prakteknya, pekerjaan proyek pada tahap awal masih akan sering mengalami penambahan bahan atau pengurangan bagian aplikasi, atau perubahan-perubahan lain.

\section{Material Collecting}

Material Collecting adalah tahap pengumpulan bahan yang sesaui dengan kebutuhan yang dikerjakan. Bahanbahan tersebut, antara lain gambar clip art, foto, animasi, video, audio, dan lain-lain yang dapat diperoleh secara gratis atau dengan pemesanan kepada pihak lain sesuai dengan rancangannya. Tahap ini dapat dikerjakan secara parallel dengan tahap assembly. Namun, pada beberapa kasus, tahap materiall collecting dan tahap assembly akan dikerjakan secara linear dan tidak paralel.

\section{Assembly}

TahapAssembly adalah tahap pembuatan semua objek atau bahan multimedia. Pembuatan aplikasi didasarkan pada tahap design, bagan alir, dan /atau struktur navigasi.

\section{Testing}

Tahap Testing (pengujian) dilakukan setelah menyelesaikan tahap pembuatan (assembly) dengan menjalankan aplikasi/program dan melihatnya apakah ada kesalahan atau tidak. Tahap pertama pada tahap ini disebut tahap pengujian alpha (alpha test) yang pengujiannya dilakukan oleh pembuat atau lingkungan pembuatnya sendiri. Setelah lolos dari pengujian alpha, pengujian beta yang melibatkan penggunaanakhirakan di lakukan.

\section{Distribution}

Pada tahap ini, aplikasi akan disimpan dalam suatu media penyimpanan. Jika media penyimpanan tidak cukupuntuk menampung aplikasinya, komprensi terhadap aplikasi tersebut akan dilakukan. Tahap ini juga dapat disebut tahap evaluasi untuk pengembangan produk yang sudah jadi supaya menjadi lebih baik. Hasil evaluasi ini dapat digunakan sebagai masukkan untuk tahap concept pada produk selajutnya.

\section{RANCANGAN APLIKASI}

Perancangan visualisasi 3d gedung STMIK Widya Cipta Dharma berbasis augmented reality pada brosus penerimaan mahasiswa baru ini menggunakan alat bantu, yaitu use case diagram, activity diagram dan sequence diagramsebagai salah satu cara untuk mempermudah dalam pembuatan aplikasi ini. 
1. Use Case Diagram Visualisai 3D Gedung STMIK Widya Cipta Dharma

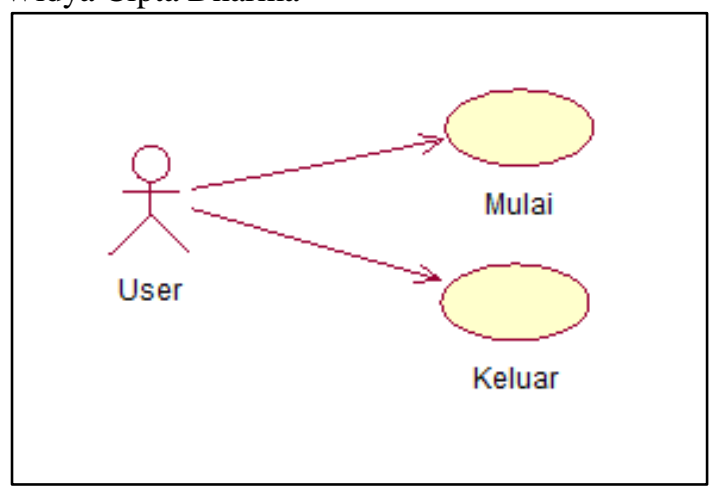

Gambar 4. Use Case Diagram

Pada gambar 4 dapat dilihat user hanya dapat melakukan 2 aksi yaitu mulai dan keluar. Dalam menu utama user dapat memilih "Mulai" untuk memulai aplikasi, dan "Keluar" untuk keluar dari aplikasi.

2. Activity Diagram Visualisai 3D Gedung STMIK Widya Cipta Dharma

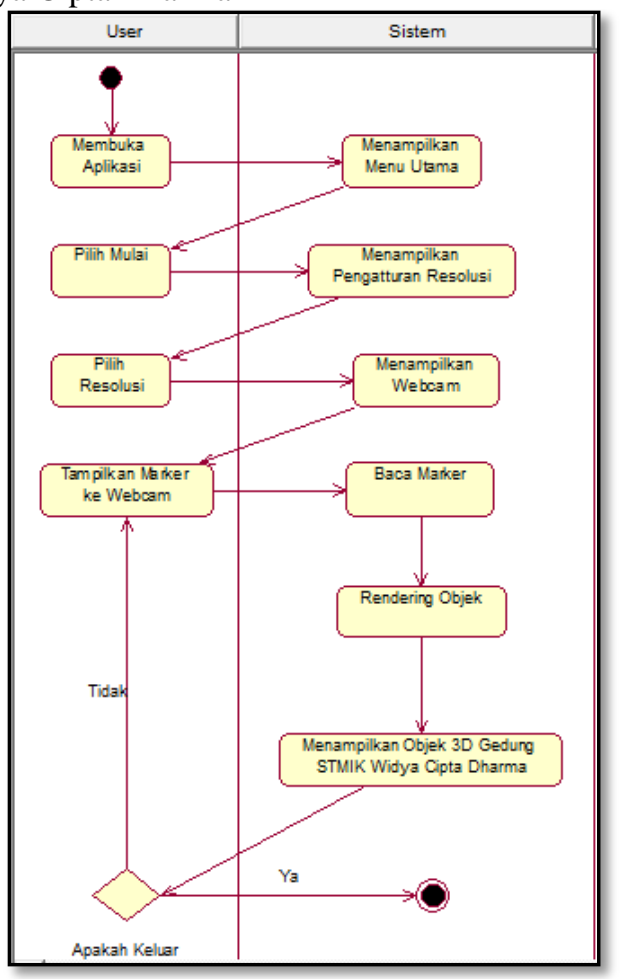

Gambar 5. Activity Diagram

Pada gambar 5 alur aktifitas yang terjadi disaat user membuka aplikasi dan sistem akan menampilkan menu utama dimana user memilih "Mulai" untuk memulai aplikasi, kemudian sistem akan menampilkan pengaturan resolusi setelah memilih resolusi webcam sistem akan menampilkan webcam. Lalu user akan menampilkan marker ke webcam dan sistem akan membaca marker lalu merendering objek 3 dimensi, setelah marker terbaca dan objek sudah di render oleh sistem maka akan tampil objek 3D gedung STMIK Widya Cipta Dharma. Jika user memilih keluar sistem akan selesai namun jika tidak maka user tetap menampilkan marker ke webcam
3. Sequence Diagram Visualisasi 3D Gedung STMIK Widya Cipta Dharma

Pada gambar 6 menunjukkan proses yang terjadi antara user dengan sistem, dimana sistem mengeksekusi setiap proses agar aplikasi dapat berjalan sesuai dengan semestinya.

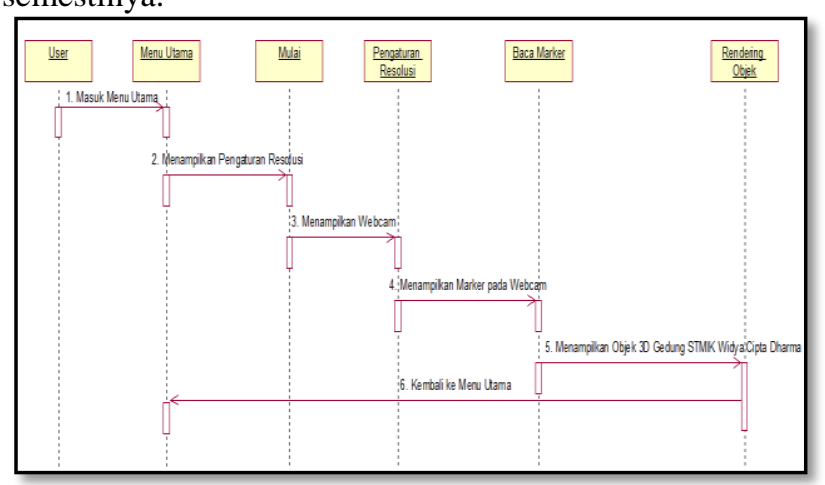

Gambar 6. Sequence Diagram

\section{IMPLEMENTASI}

Hasil implementasi berdasarkan analisis dan perancangan adalah sebagai berikut :

1. Tampilan Objek 3 Dimensi Gedung STMIK Widya Cipta Dharma Berbasis Augmented Reality

Objek 3 dimensi gedung STMIK Widya Cipta Dharma menampilkan keseluruhan gedung utama yang dimiliki oleh kampus STMIK Widya Cipta Dharma sesuai dengan observasi lapangan. Dapat dilihat pada gambar 7

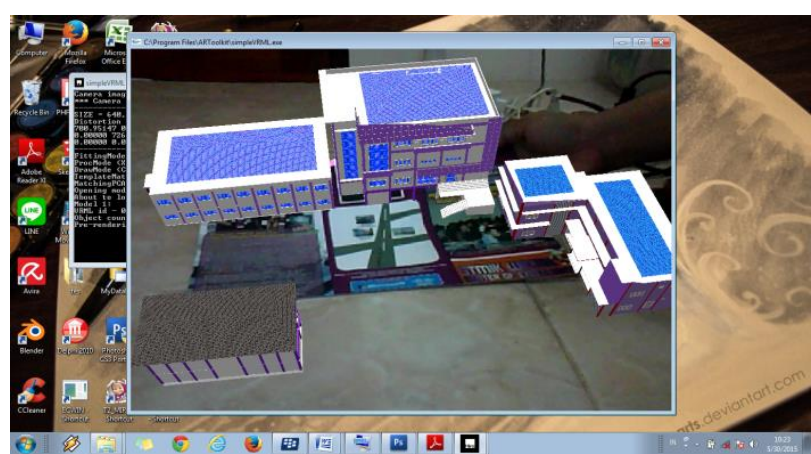

Gambar 7. Tampilan objek 3D gedung STMIK Widya Cipta Dharma

2. Tampilan Brosur Penerimaan Mahasiswa Baru Berbasis Augmented Reality

Brosur ini memiliki dua sisi yaitu sisi luar dan sisi dalam, desain brosur ini menggunakan desain yang sudah ada kemudian ditambahkan dengan penambahan fitur augmented reality pada brosur sisi luar dan menghilangkan gambar gedung yang dipergunakan sebagai ilustrasi dari gedung kampus STMIK Widya Cipta Dharma. Brosur sisi dalam berisi informasi terkait fasilitas kampus, persyaratan dan biaya pendaftaran seperti yang terlihat pada gambar 8 . 


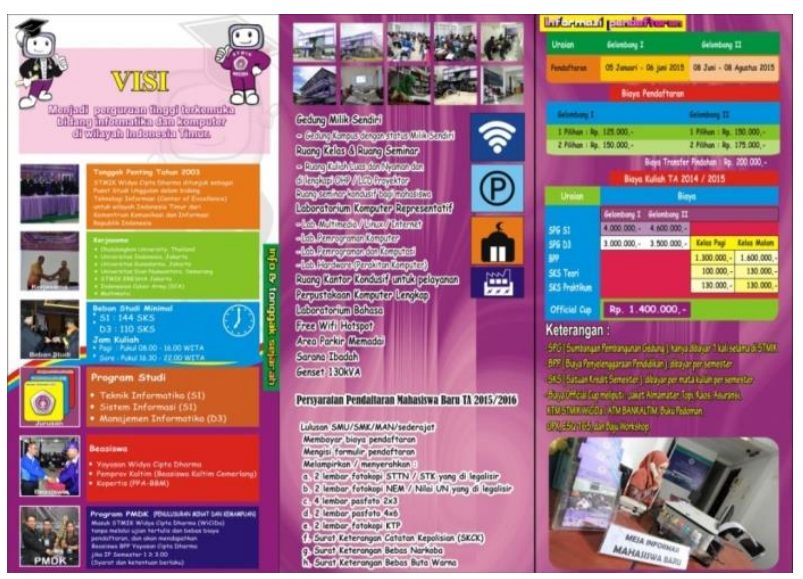

Gambar 8. Tampilan brosur sisi dalam

Pada brosur sisi luar terdapat informasi lokasi kampus dan informasi masih seputar pendaftaran mahasiswa baru, dapat dilihat pada gambar 9. Serta ditambahkan marker di atas gambar denah lokasi kampus, untuk menampilkan visualisasi gedung 3D STMIK Widya Cipta Dharma

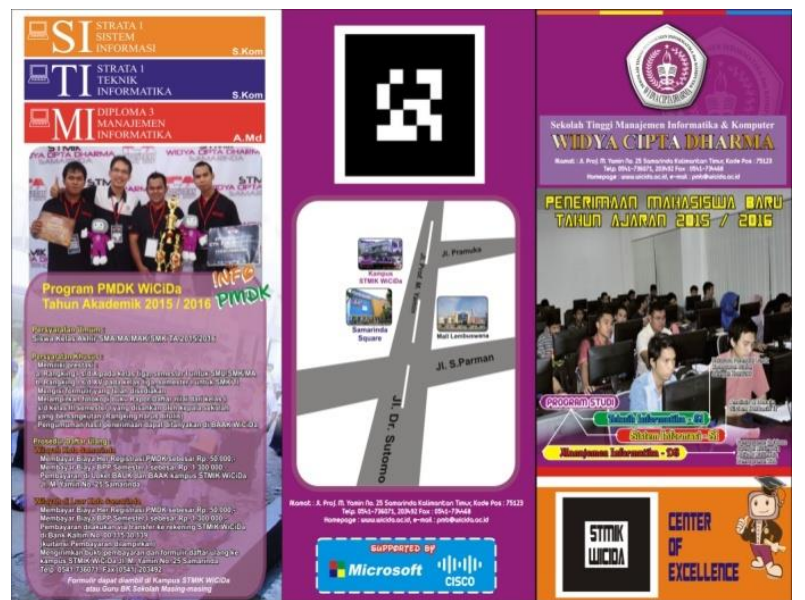

Gambar 9. Tampilan brosur sisi luar dengan marker AR Gedung 3D

\section{KESIMPULAN}

Berdasarkan uraian dari hasil pembahasan maka dapat disimpulkan bahwa pembuatan pembelajaran bangun ruang berbasis augmented reality dengan metode marker augmented reality sebagai berikut :

1. Untuk membangun visualisasi 3D gedung STMIK Widya Cipta Dharma berbasis augmented reality pada brosur penerimaan mahasiswa baru, diawali dengan penginstalan software pendukung augmented reality yaitu ARToolKit. Merancang desain 3D objek gedung STMIK Widya Cipta Dharma menggunakan Google SketchUp, merancang desain marker dan desain brosur penerimaan mahasiswa baru menggunakan Adobe PhotoShop CS3.

2. Visualisasi 3D Gedung STMIK Widya Cipta Dharma Berbasis Augmented Reality pada Brosur Penerimaan Mahasiswa Baru ini dapat menjadi salah satu media alternatif untuk promosi pada calon mahasiswa baru. Dengan tampilan desain 3 dimensi kampus STMIK
Widya Cipta Dharma tersebut diharapkan dapat menaikkan minat calon mahasiswa baru dan memperkenalkan bangunan STMIK Widya Cipta Dharma dengan cara yang lebih interaktif.

\section{SARAN}

Adapun tindak lanjut yang diharapkan berdasarkan penelitian ini adalah :

1. Brosur ini dapat dikembangkan dan media untuk menampilkannyapun dapat dikembangkan untuk berbagai jenis platform contohnya smartphone android.

2. Menambahkan informasi detail ruangan yang lebih lengkap pada objek 3 dimensi gedung STMIK Widya Cipta Dharma.

3. Menambahkan fitur animasi 3 dimensi yang lebih menarik agar tampilan tidak terlalu monoton dengan hanya tampilan berupa gedung, sehingga menjadi media promosi yang lebih interaktif.

\section{DAFTAR PUSTAKA}

Andriyadi, Anggi, 2012. Augmented Reality With ARToolkit. Jakarta: NulisBuku

Azuma, R.T. 2014. A Survey Of Augmented Reality : Presence Teleoperators and Virtual Environments Hughes Research Laboratories

Binanto, Iwan. 2010, Multimedia Digital - Dasar Teori dan Pengembangannya. Yogyakarta: Andi.

Chari, dkk. 2008. Augmented Reality Using Over Segmentation : Center for Visual Information Technology, International Institute of Information Technology

Darmawan, Djoko. 2009, Google SketchUp Mudah dan Cepat Menggambar 3Dimensi, Yogyakarta: CV. Andi Offset.

Manullang, Rio. 2014, Desain 3D Rumah Minimalis degan Google Sketchup, Jakarta: PT. Elex Media Komputindo

Pressman, R. 2010 Software Engineering: A Practitioner's Approach. McGraw-Hill.

Vaughan, Tay. 2011. Multimedia: Making It Work 8th Edition. New York : McGraw Hill.

Villagomez. G. 2010. Augmented Reality. University of Kansas.

Yan, dkk. 2011. Research on Augmented Reality Display Method of Scientific Exhibits : DigitalEntertaiment Research Center.China : Nanjing Normal University 